KAPLAN, C. (1958). J. gen. Microbiol. 18, 58-63

\title{
The Heat Inactivation of Vaccinia Virus
}

\author{
By C. KAPLAN \\ The Lister Institute of Preventive Medicine, Elstree, Hertfordshire
}

SUMMARY: Heat inactivation curves of vaccinia virus between $50^{\circ}$ and $60^{\circ}$ indicate that the virus is heterogeneous in its heat sensitivity. The proportion of heatresistant particles varies inversely with the temperature of exposure. The inactivation of heat-sensitive virus is temperature dependent and seems to be a first-order reaction, while the heat-resistant fraction is inactivated at a constant slow rate unrelated to temperature over the range $50^{\circ}-60^{\circ}$.

The work reported here is part of a larger investigation of virus inactivation by physical agents including ultraviolet and ionizing radiations, under conditions that do not destroy antigenicity (McClean, 1945; Collier, McClean \& Vallet, 1956). The heat inactivation of vaccinia virus was determined as a preliminary to testing the protective antigenicity of heat inactivated vaccines.

\section{METHODS}

Virus. Most of the experiments were done with the Lister Institute strain of vaccinia virus adapted to the chick embryo; two experiments were done with the WR mouse neuro-adapted strain of virus. Infected chorioallantoic membranes were extracted in dilute McIlvaine buffer by grinding with sterile powdered neutral glass. Extracts were centrifuged at $1000 \mathrm{~g}$ for $15 \mathrm{~min}$. to clear them of debris, titrated and stored at $4^{\circ}$. For inactivation, extracts were diluted to a titre between about $10^{7}$ and $10^{8}$ infective units $/ \mathrm{ml}$.

Experimental procedure. One ml. samples of virus were heated in small, thin-walled test tubes in a water bath accurate to $\pm \mathbf{0 \cdot 2 ^ { \circ }}$. Samples were removed from the bath at intervals and immediately cooled in a melting ice bath. They were stored at $4^{\circ}$ until infectivity titrations were made: this was generally within a few hours, but on a few occasions there was an interval of 2 or 3 days.

Infectivity titrations were made by pock counts on the chorioallantoic membranes of 12- or 13-day chick embryos. The refinements of membrane handling technique described by Westwood, Phipps \& Boulter (1957) were used. In titrations of WR strain 3-day instead of the usual 2-day incubation was used, because after 2 days the pocks were pale and poorly developed.

Diluent. All extractions and dilutions were made in McIlvaine's phosphate + citrate buffer, $\mathrm{pH} 7 \cdot 2,0 \cdot 004 \mathrm{M}$-phosphate:

In graphs of the results each point is the arithmetic mean of at least four experiments unless otherwise stated. The results are plotted as $\log V_{0} / V$ against time, where $V_{0}$ is the original concentration and $V$ the concentration at any time $t$. This enables all the inactivation curves to be given a common 
origin for ease of comparison, and it is also one of the terms of the first-order reaction rate equation: $\log V_{0} / V=K t / 2 \cdot 3$.

\section{RESULTS}

At $60^{\circ}$ there is an initial rapid inactivation of most of the virus, and a slower inactivation of a small residual fraction. An experiment was done to see whether this greater resistance to heat was genetically determined. From a membrane inoculated with a sample heated for 60 min. a single pock was taken and extracted in $1 \mathrm{ml}$. of buffer. The bacteriologically sterile extract

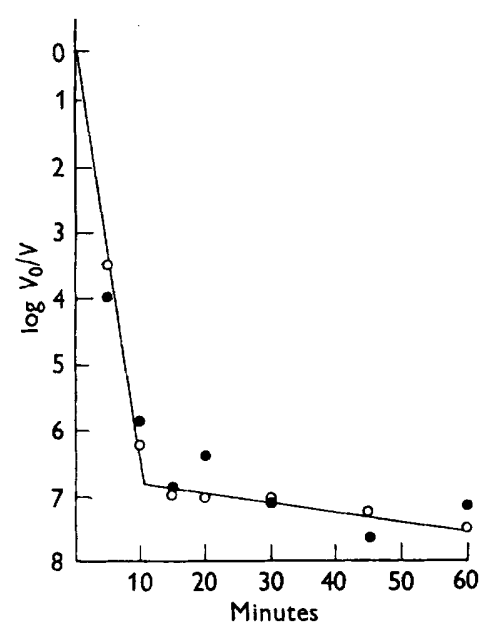

Fig. 1

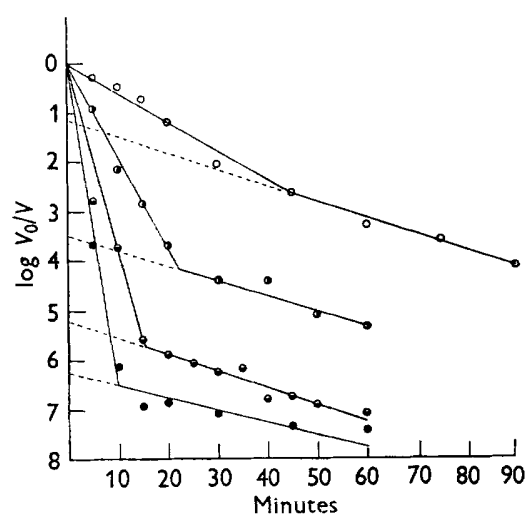

Fig. 2

Fig. 1. Inactivation of vaccinia virus at $60^{\circ}$. $O$, 'Original virus'; 3 experiments; $\bullet$, progeny of 'heat resistant' virus : 4 experiments; $V_{0}$, initial virus concentration; $V=$ virus concentration at time $t$.

Fig. 2. Inactivation curves of vaccinia virus extrapolated to theoretical initial concentration of heat-resistant fraction: $O, 50^{\circ}: 6$ experiments; $O, 52.5^{\circ}: 4$ experiments; $\ominus, 55^{\circ}: 6$ experiments; $\varphi, 60^{\circ}: 7$ experiments.

was passaged undiluted on the chorioallantoic membranes of five 12-day embryos and 2 days later the virus was extracted from the infected membranes. Fig. 1 shows the course of inactivation at $60^{\circ}$ of the original virus and of the clone derived from the single pock. In four tests the inactivation at $60^{\circ}$ of preparations descended from 'heat-resistant' virus did not differ from that of the original virus.

The clone derived from 'heat-resistant' virus was inactivated at $50^{\circ}$, $52 \cdot 5^{\circ}$ and $55^{\circ}$. Over the range $50^{\circ}-60^{\circ}$ inactivation appeared to proceed as a first-order reaction until more than $90 \%$ of the infectivity had been destroyed (Fig. 2). The inactivation curves suggest two processes, and are consistent with the view that the second process not only succeeds the first but may start simultaneously with it. The velocity constants of both the fast and the slow inactivation, calculated for each temperature (Table 1), show that the rate of fast inactivation is dependent on temperature, and that of the slow 
inactivation of the heat resistant survivors is apparently independent of temperature-at least over the $10^{\circ}$ range investigated. Fig. 3, a composite of several experiments at $50^{\circ}$, shows two inflexions, indicating two changes of inactivation rate. This phenomenon was observed in four experiments at $50^{\circ}$ and may indeed prove to be real. In this connexion it may be noted that we have obtained similar double inflexions in the curves of inactivation of vaccinia virus by $\gamma$ rays (unpublished work). This was not looked for at any other temperature.

Table 1. Velocity constants of fast and slow inactivations of vaccinia virus showing temperature dependence of fast reaction $\left(K_{f}\right)$ and lack of temperature dependence of slow reaction $\left(\boldsymbol{K}_{s}\right)$

$\begin{array}{ccc}\begin{array}{c}\text { Temperature } \\ \left({ }^{\circ} \mathrm{C} .\right)\end{array} & \begin{array}{c}K_{f} \\ \left(\min ^{-1}\right)\end{array} & \begin{array}{c}K_{s} \\ \left(\min ^{-1}\right)\end{array} \\ 50 & 0.14 & 0.07 \\ 52.5 & 0.42 & 0.073 \\ 55 & 0.87 & 0.074 \\ 60 & 1.48 & 0.056\end{array}$

Table 2. Activation energies $(E)$ of heat-sensitive fraction showing decrease of $E$ as the temperature of exposure increases

$\begin{array}{cc}\text { Temperature } & E \\ \text { range }\left({ }^{\circ} \mathrm{C} .\right) & \left(\text { cal. } / \text { mole } /{ }^{\circ} \mathrm{C} \text {.) }\right. \\ \mathbf{5 0 - 5 2 \cdot 5} & \mathbf{9 1 , 8 0 0} \\ \mathbf{5 2 \cdot 5 - 5 5} & \mathbf{6 1 , 6 0 0} \\ \mathbf{5 5 - 6 0} & \mathbf{2 3 , 0 0 0} \\ \mathbf{5 0 - 6 0} & \mathbf{5 0 , 2 7 0}\end{array}$

The energies of activation $(E)$ for the various temperature ranges investigated were calculated from the velocity constants of the fast reactions (Table 2). The decrease in activation energy over the temperature range studied suggests that as temperature increases either a smaller input of energy is necessary to induce physicochemical changes in the virus or there is less virus present which is susceptible to heat inactivation.

The results of two experiments with the WR strain of virus at $55^{\circ}$ are similar to those with the Lister Institute strain at $55^{\circ}$ (Fig. 4). Clearly, strains which behave very differently in infected hosts may have similar susceptibility to heat.

\section{DISCUSSION}

It has been generally assumed that the inactivation of viruses at different temperatures is exponential (Luria, 1953). Adams (1949) found that the inactivation of bacteriophage by heat was exponential, and increased very rapidly over the $10^{\circ}$ range from $63^{\circ}$ to $73^{\circ}$. Bronson \& Parker (1943) reached similar conclusions about the inactivation of myxoma virus. Fenner (1953) had similar results with two strains of vaccinia virus. He did not, however, continue his experiments long enough to reach zero infectivity; this point was estimated by graphic extrapolation of the line obtained in short-period 


\section{Heat inactivation of vaccinia virus}

experiments. Bourdillon (1944), working with a partially purified mousebrain preparation of Columbia SK virus, obtained a family of inactivation curves at $49 \cdot 5^{\circ}, 56 \cdot 5^{\circ}$ and $63^{\circ}$. His results suggested that the reaction did not follow first-order kinetics, but are insufficient to allow any firm conclusions to be drawn from them. Lauffer \& Carnelly (1945) and Scott \& Lauffer (1946) were unable to show that influenza virus haemagglutinin was destroyed as a first-order reaction when heated. They managed to obtain a linear relationship

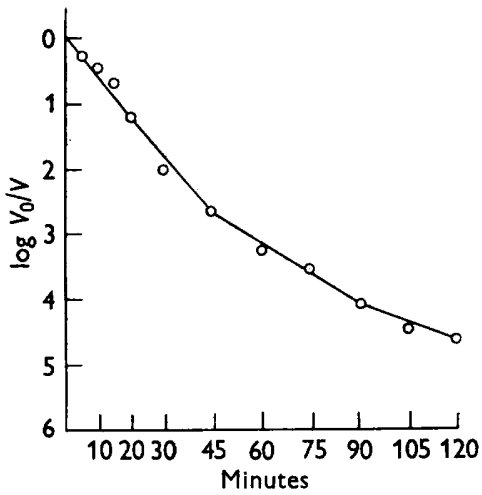

Fig. 3

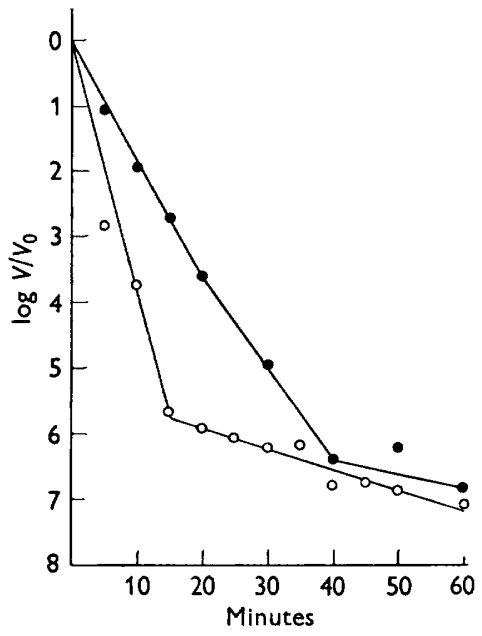

Fig. 4

Fig. 3. Inactivation at $50^{\circ}$ : composite of two $60 \mathrm{~min}$. experiments and four $120 \mathrm{~min}$ experiments.

Fig. 4. Inactivation of two strains of vaccinia virus at $55^{\circ} .0$, Lister strain: 6 experiments; e, WR strain: 2 experiments.

by plotting the reciprocal of the square root of residual haemagglutinating activity against time. This relationship indicates that influenza haemagglutinin is heterogeneous in its heat sensitivity - a state of affairs readily ascertained by less circuitous methods.

Lauffer, Wheatly \& Robinson (1949) inactivated influenza virus at various temperatures in the presence of urea or formaldehyde. In only one case did they continue an experiment for as long as $\mathbf{3 0} \mathrm{min}$. They made no comment about heterogeneity of response to heat, but since the lowest titres reached in their experiments were in the region of $10^{4} \mathrm{LD} 50$ doses they may not have reached the level at which heterogeneity would be manifest. Lauffer \& Wheatly (1951) re-investigated the problem of the alleged $3 / 2$ order reaction with influenza haemagglutinin and concluded that the behaviour of their virus was conditioned by the presence, in even the most highly purified preparations, of a mixture of rapidly and slowly reacting haemagglutinin particles. Bachrach, Breese, Callis, Hess \& Patty (1957) showed that foot-and-mouth disease virus has a heat inactivation pattern very similar to that found by us for vaccinia.

Our results suggest that vaccinia virus preparations also contain particles 
with two or three sensitivities to heat. It is more likely, however, that a given vaccinia virus population contains a great preponderance of particles which are rapidly inactivated and a smaller proportion of varying susceptibility to heat. This can be seen in Fig. 2. in which the resistant fraction is decreased from about $10 \%$ at $50^{\circ}$ to less than $0.000001 \%$ at $60^{\circ}$. The values of $E$ in Table 2 also suggest that as the temperature increases there is a progressively smaller proportion of heat-resistant particles which have to be endowed with enough energy to raise them to the activated state in which changes in molecular structure may be expected to occur.

The suggestion that virus populations are heterogeneous in various respects has been made for several animal viruses. Smith \& Cohen (1956) separated influenza virus strains into rapidly- and slowly-eluting components, and obtained fractions unable to elute spontaneously from human red cells. The progeny both of rapidly-eluting and of non-eluting fractions proved in each case to be of mixed elution behaviour, i.e. similar to the original strain. Gard (1957), in a discussion on the chemical inactivation of viruses by formaldehyde, concluded that the manifest divergence from first-order kinetics of not only poliomyelitis virus but also tobacco mosaic virus and probably influenza virus was evidence of heterogeneity He put forward two theories: that heterogeneity is genetically determined, or that it is induced by the exposure to formaldehyde. He considered that the fact that genetically homogeneous strains of virus could not be obtained was evidence against the first and in favour of the second hypothesis. Although our results agree with Gard's in that resistance to inactivation is not genetically controlled, heterogeneity of various types is not excluded as a normal attribute of virus populations. Although it is possible that the coagulating action of formaldehyde renders surviving virus steadily less susceptible to other chemical actions, it is very difficult to imagine any way in which exposure to heat could make the exposed virus particles more resistant to heat.

No explanation can be offered for the fact that the inactivation rate of the resistant fraction of virus is independent of temperature over the range studied. It is possible that some light may be shed on this by studies of other methods of inactivation. We obtained curves of similar shape when vaccinia virus was exposed to large doses of $\gamma$-radiation. Whatever its explanation, there is little doubt that the pattern of inactivation of this virus, and of others (Bourdillon, 1944; Lauffer \& Carnelly, 1945; Scott \& Lauffer, 1946; Lauffer \& Wheatly, 1951; Woese, 1956; Timm, McLean, Kupsky \& Hook, 1956; Taylor et al. 1957) is a character of many viruses when they are inactivated by agents as different as heat, formaldehyde and ultraviolet radiation. This means that the margin between inactivation of infectivity and destruction of antigenicity may often be too small to be of practical value. It also means that, since small numbers of virus particles may resist inactivation for long periods, sensitive and stringent tests must be used to detect this minute proportion of survivors in inactivated virus vaccines. This point has recently been made by Gard and other workers in the poliomyelitis vaccine field, but it is a subject of such great practical importance that it cannot be overstressed. 
I wish to thank Miss V. Finnegan and Mr J. Squires for their technical assistance; and Dr R. H. Painter for several interesting and profitable discussions.

\section{REFERENCES}

Adams, M. H. (1949). The stability of bacterial viruses in solutions of salts. J. gen. Physiol. 32, 579.

Bachrach, H. L., Breese, S. S., Callis, J. J., Hess, W. R. \& Patty R. E. (1957). Inactivation of foot-and-mouth disease virus by $\mathrm{pH}$ and temperature changes and by formaldehyde. Proc. Soc. exp. Biol., N.Y. 95, 147.

Bourdillon, J. (1944). Heat inactivation of the murine strain of SK poliomyelitis virus. Arch. Biochem. 3, 299.

Bronson, L. H. \& Parker, R. F. (1943). The inactivation of the virus of infectious myxomatosis by heat. J. Bact, 45,177 .

Collier, L. H., McClean, D. \& Vallet, L. (1956). The antigenicity of ultra-violet irradiated vaccinia virus. J. Hyg., Camb. 53, 513.

FenNer, F. (1953). Classification of myxoma and fibroma viruses. Nature, Lond. 171, 562 .

GARD, S. (1957). Chemical inactivation of viruses, In The Nature of Viruses. Ed., G. E. W. Wolstenholme and E. C. P. Millar. London: Churchill.

Lauffer, M. A. \& Carnelly, H. L. (1945). Thermal destruction of influenza A virus haemagglutinin. I. The kinetic process. Arch. Biochem. 8, 265.

Lauffer, M. A. \& Wheatly, M. (1951). Destruction and denaturation of influenza A virus. Arch. Biochem. Biophys. 32, 436.

Lauffer, M. A., Wheatly, M. \& Robinson, G. (1949). The destruction of influenza A virus infectivity by urea. Arch. Biochem. 22, 467.

Luria, S. E. (1953). General Virology. New York: Wiley.

McClean, D. (1945). The antigenicity of vaccinia virus inactivated with alcohol. J. Path. Bact. 57, 261.

ScotT, E. M. \& Lauffer, M. A. (1946). Thermal destruction of influenza A virus haemagglutinin. III. The effect of urea. Arch. Biochem. 11, 179.

Smith, W. \& Cohen, A. (1956). The enzymic activity of influenza viruses. Brit. $J$. exp. Path. 37, 612.

Taylor, A. R., Kay, W. W., Mclean, I. W., Oppenheimer, F. \& Stimpert, F. D. (1957). Effect of ultraviolet light on poliomyelitis virus. J. Immunol, 78, 45.

Timm, E. A., McLean, I. W., Kupsky, C. H. \& Hook, A. E. (1956). The nature of the formalin inactivation of poliomyelitis virus. J. Immunol, 77, 444.

Westwood, J. C. N., Phipps, P. H. \& Boulter, E. A. (1957). The titration of vaccinia virus on the chorioallantoic membrane of the developing chick embryo. J. Hyg., Camb. 55, 123.

Woese, C. R. (1956). Heat inactivation studies on animal viruses. I. The inactivation of virus haemagglutinin. Arch. Biochem. Biophys. 63, 212. 